\title{
CHAPTER FOURTEEN
}

\section{Comparative Observations on the Near Eastern Epic Traditions}

\author{
Jack M. Sasson
}

We must not doubt that stories were told and enjoyed long before humans learned how to transpose what the ear hears into what the eye sees. Whether brief or developed, transmitted verbatim or embellished, these tales were likely sung, chanted, intoned, or declaimed, with or without bodily accompaniments. Neither must we doubt that long before what we call writing (characters with visual codes) developed just over 5,000 years ago, people had found many ways to stimulate their memory of words they have heard: through distinctly shaped tokens, via paintings or artifacts, evocative music, or the dance. We may imagine, too, that at the dawn of history the literature that we want to call "epic" had been evolving for millennia. People gathered around fires and made their world more human by telling and hearing stories about worthy deeds, gained or lost. Therefore, when in this chapter we focus on the ancient Near East's manifestation of the epic tradition, we have already lost the thread of its earliest development.

The "Ancient Near East" (henceforth ANE) is a vast and unwieldy setting from which to draw the material for our discussion. The label itself is of relatively recent coinage and has no equivalent in ancient documents. Beyond a unity of time and space and a participation in technological developments, the cultures were regionally distinct, in the languages they spoke, in the religions they professed, in the governments they shaped, in their art, in their architecture and, as we shall see, in their literature. Let us arbitrarily but reasonably limit the time span to the two and half millennia before the Christian era and the area to those in Mesopotamia, Anatolia, Canaan, Israel, and Egypt. The comments will address selected issues about diversity of contexts, process in the development of epic literature, and literary features.

\section{Diversity}

\section{Languages}

We are told by linguists that each century witnesses regressively the extinction of many more languages than are generated. This is true of the ANE as well, where names of places and of individuals often betray unknown linguistic families. Some of the languages we know from recovery of documents resist attachment to families (Sumerian, Hurrian, Hattic, Elamite). Others represent the earliest written representatives of Indo-European (Hittite, Luwian). Most belonged to branches of Semitic that have not survived the times: 
Akkadian, Ugaritic, Phoenician, biblical Hebrew. One, Egyptian, evolved into Coptic, and now barely survives.

With their capacities and idiosyncrasies, these languages play a major role in shaping thought patterns (perhaps also vice versa), and although we want to believe that story lines, themes, and motifs can survive crossing language barriers, the evidence is not encouraging. We debate the very few tales that betray their importation from other cultures. For example, Elkunirsha and Ashertu and Astarte and the Sea, both containing Canaanite themes and motifs, have been found respectively in Hatti (Anatolia) and Egypt, but not yet in their own homeland. For the Gilgamesh Epic, there are Hurrian and Hittite renderings, the latter even containing motifs probably not available either to the Old Babylonian original or the contemporaneous Middle Babylonian version of the epic (Beckman 2003). Yet it remains a fact that before the Hellenistic period literary works that are simply translated (rather than, say, adapted or recast) for foreign audiences are scarce.

This is not to say that fluency in more than one language was abnormal in the ANE. In fact, trade and diplomacy depended on such capacity, and armies brought their own tongues into occupied territories. Bilingualism (even multilingualism) could not have been rare; but the available documents written in more than one language had limited goals. Aside from dictionary compilations destined for scribes, bilingual documents come from multiethnic communities, and they preserve mostly cultic materials, such as prayers, omens, rituals, and mythic etiologies. To claim the prestige of a dominant tradition or to mollify suzerains, such rulers as the Hittite Hattusili I, the Elamite Puzur-Inšušinak, the Etruscan Thefaries Velianas, the Syrians Azatiwada of Karatepe and Hadad-Izri of Sikanu, commissioned official pronouncements in two languages, their own as well as in the prestige one then current. A good number of bilinguals from Mesopotamia, including fawning letters or poems in praise of gods and kings, were written both in Akkadian and Sumerian, the latter a language that had lost native fluency late in the third millennium BCE.

The ANE languages we know most about (Sumerian, Akkadian, Egyptian, Ugaritic, Hittite, Hebrew) come to us with complications. The Bible's Hebrew has been manipulated by generations of scribes; the recording of its consonants occurred much earlier than its vowels, resulting in a composite language that barely approximates how it originally sounded. Despite the homogenizing influence of scribal schooling, the languages of Mesopotamia are rich in dialects (even two that are major: Assyrian and Babylonian). But they also include arrangements (not dialects) that are peculiar to learned compositions: Sumerian breaks into Emesal (etymology disputed, but once thought to be a woman's language), while Akkadian displays a "hymnic-epic" mode that exaggerates poetics. Such manifestations limit successful exportation of narratives, if only because they challenge understanding by the non-initiated.

Languages control the way narratives are shaped. Semitic languages in all their dialects are poor in abstraction, relatively ambiguous syntactically, and fond of circumlocutions. How such idiosyncrasies affected the production of literature is hard to say; but it is observable that Semitic narratives avoided physical descriptions, whether of people or places, rarely made the age of protagonists crucial to a story, and seldom attributed introspection to characters. The same can be said about Egyptian storytelling. Yet languages and their eccentricities are not alone in controlling the forms narratives take. Script and writing media are no less crucial.

\section{Scripts}

What is striking about the scripts of the ANE is their deficiency. Not one of the scripts used before the first millennium CE conveys accurately what was heard. Many of them give us 
consonants (not a complete set of phonemes at that) but not vowels - for example Egyptian, Ugaritic, Hebrew, Aramaic, and Phoenician. (Egyptian scribes compensated through an elaborate scheme of complements and determinatives, eventually even devising, but not successfully applying, a syllabic series of signs.) We know from the history of biblical interpretation that the limitations of such scripts generated interpretive problems in antiquity; the more so for us. Ugaritic narratives, for example, are not for the faint, and determining what they say is more of a scholarly convention than is admitted. Sumerian is still difficult to assess and there are almost as many grammars for it as there are Sumerologists. Akkadian and Hittite adapted the scripts of other languages; but in doing so they lost a capacity to fully deploy it phonologically. The only Aramaic candidate for inclusion in our category, The Two Princes, is preserved in Egyptian demotic script, so compounding our problem in establishing its basic meaning. (See below.) The consequence of script complications is twofold: in antiquity, the transfer of narratives across languages might have not have fared well if it depended on the written rather than the spoken word; in our own days, translations from some ancient languages may not be as secure as we might like them to be.

\section{Media}

Stone, wood, skins, and bones were among the writing materials in the ANE. In all regions, stone (of all varieties) was preferred for monumental inscriptions. Clay was the choice writing medium in Mesopotamia and Khatti, papyrus in Egypt, a combination of both in Canaan. Chalked or waxed wooden boards were often used but few have survived. Sumerians shaped compositions to fit on single tablets and so avoided the elaborate storage and retrieval systems for narratives requiring more than one tablet. Not uncommon, however, were single-tablets stories that shared the same protagonist (for example, five so far for the Sumerian Gilgamesh). Such single-tablets tales average 500 lines (for example, the size of four Sumerian tablets about Enmerkar and Lugalbanda). Unusual are the two $60 \mathrm{cms}$ high clay cylinders with a 1,360 "lines" that recounted Gudea's building of a temple in Lagash.

Akkadian compositions, however, could stretch over a number of tablets. The longest "heroic" narrative in Akkadian is a version of the Gilgamesh epic that required twelve tablets. The whole is estimated to be about 3,000 lines (20 percent of which is still missing), so a fraction of the Illiad (15,600 lines) or the Odyssey (12,000 lines). The Old Babylonian version of Atrahasis, is shorter: 1,245 lines over three tablets, according to the precise count of Nur-Aya, a scribe of King Ammisaduqa of Babylon (seventeenth century в СЕ). The longest composition in Ugaritic cuneiform, Baal and Anat, stretches over six multi-column tablets that might have contained a total of 3,000 lines; but it is not yet certain that the whole was a single unit. Other narratives (Keret and Aqhat) are much more modest, three tablets each, with anywhere between 250 and 350 lines per tablet. Narratives in Hittite literature tend to be even briefer; the longest, the Song of Ullikumi, covers three tablets.

In Egypt and Israel scribes had a broad selection of writing material, but they wrote and copied sacred literature on papyrus scrolls. Egyptian papyri can reach 40 meters, but narratives occupied much smaller dimensions. Sporadically Egyptian scribes also used leather, its technology having been perfected late in the third millennium BCE. Israel probably adopted leather rather late; but as scrolls could attain 10 meters and still retain their integrity, the potential for threading a single subject over a full roll (if not also in a series of rolls, such as the Five Books of Moses), gave narratives a density and complexity far beyond their deployment in other media. Israel could, therefore, unfold its story over millennia and across a vast canvas, filling it with themes that repeat, characters that prove 
paradigmatic, and events that are verisimilar. Because they are embedded within a single story, even its laws, regulations, and moral exhortations become part of a narrative with a single focus: the only God that ever was is committed to the welfare of a single, albeit unpromising, people.

\section{Literacy}

Literacy has many levels. Between the illiterate (no ability to read or write) and the learned (creative reader and writer), there are people who can recognize symbols but not read, read but not write, or do both but within specific genres. Those who could record original, esoteric, and abstract thought were probably rare. (We have notices from Old Babylonian Mari, a relatively literate age, that kings scoured their empires for the few scribes who could work in literary languages.) What is striking, however, is that the level and range of literacy do not seem tied to the complexity of a script. It is very likely, therefore, that illiteracy went deeper (or at least just as deep) in urban medieval Europe, where the alphabet reigned, than in urban Babylon with its cumbersome cuneiform. It might also be noted that antiquity esteemed varieties of literacy that are scarcely acknowledged among us, for example the capacity to read omens in the sky or to decipher markings on the innards of animals, both of which required the assimilation of much traditional lore only a fraction of which was written in our sense.

Many scholars have offered estimates of the percentage of literates in given populations; these estimates are all speculative and obey the swings of the scholarly pendulum, although currently the trend is to find it wider than previously allowed. (Overview in Vanstiphout 1995. For the Levant, see Parpola 1997: 320-1; Wilcke 2000; Charpin 2003: 502-3; for Egypt, see Lesko 1990 and Wente 1995.) Within individual communities, the number of literates may have been affected by taste and political institutions. From mid-third millennium Ebla (near Aleppo in Syria) comes a repertoire of texts that betrays heavy dependence on Sumerian literary taste. Whether this condition reflects folk, elite, expatriate, or a merely scribal interest is not easy to tell; but it must certainly have required expansion of school facilities. Centuries later, as Mesopotamia became home to multinational empires, the centers of literary knowledge moved from the scribal schools, associated with private quarters, to those within temples and palaces. There remains continuity in copying the inherited documents; but creativity begins to gravitate toward the production of omens and ritual texts, while heroic narratives (Etana, Atrabasis, Adapa) are folded within incantations (Michalowski 1992: 233-40).

\section{Orality/Aurality}

The above observation is of import to a debate on the composition, reception, and transmission of literature deemed heroic or even mythic that has claimed attention ever since Milman Parry and Albert Lord first investigated the relationship of oral tradition to Homeric studies. Parry's basic premise is that our received Greek epics betray evidence that illiterate bards crafted and orally delivered heroic and mythic literature by improvising on absorbed folklore and by using a formulaic yet poetic language. The earliest audiences marveled at what these bards told, but they also delighted in finding a correspondence between their own worldview and that of the past. The premise here is that unlike written literature, which can lie dormant for centuries, orally forged literature cannot ever be antiquarian or historically distant from its presentation.

Over the years, these tenets have been critiqued and denied by classicists, with defenders offering modifications galore on such issues as premeditation, memorization, dictation, presentation, and performance. The same debate has made a universal impact on the study 
of literature, including that of the ANE. Parry and Lord could offer their hypothesis because all the Homeric manuscripts were appreciably later than the date of their presumed composition (generally eighth century BCE) let alone of their inspiration (sometimes claimed to be Mycenaean). However, except for the biblical material, which parallels the Homeric epic in its complex transmission history and in its lack of chronological anchoring, the literatures from Mesopotamia, Ugarit, Hatti, and Egypt are excavated from well-defined contexts, even if one cannot always pinpoint the process of transmission before they were committed to writing. Many compositions occur in critical recensions or even multiple versions, and they betray active scribal (thus, written) reshaping. It is not surprising, therefore, that the sharpest conviction about the orality/aurality of Hebrew literature originated at Harvard, where Lord was spreading the gospel.

Other ANE specialists have been ambivalent about the matter, most often ignoring the issue as it pertains to the creation of texts, but delivering diverse opinions as it applies to the presentation of compositions. Sumerian compositions tend toward economy of words and location, attachment to doxological formulation, and narrative pivots at regular interval, hence easing aural absorption (Vanstiphout 1995). Yet a significant portion of this literature was crafted when Sumerian was no longer a living language, so unlikely to be based on living transmission, dispensed by illiterate bards, or appreciated by multilingual audiences. (One notable exception is the imperfectly understood Lugalbanda and Ninsun from the Early Dynastic period when Sumerian was still spoken. It may have told the birth of Gilgamesh, traditionally Lugalbanda's son!) Moreover, Sumerian literature, while full of word-pairing and fond of strophic repetition, is not particularly formulaic. It is dense in imagery (for us, much of it far-fetched) that impacted emotionally but was hardly easy on the ears. It was also full of the long repetitions that would have put an insomniac to sleep but easy on the reader who might simply skip them.

\section{Genre}

There is also the problem of determining what kind of literature is "epic". The best scribes of antiquity were multilingual and were fond of categorizing and classifying objects known to them, from animals to the zodiac. They certainly could have crafted a theoretical language to discuss literature or developed labels by which to discriminate among compositions. The mystery is that they hardly bothered. (Contrast Black 1998: 25 and Parkinson 2002: 32-6, 108-12.) Each ANE culture attached a rudimentary roster of labels to some of its compositions. Yet for us these rubrics (often given as subscriptions or in colophons) are maddeningly imprecise or ubiquitous, drawing haphazard scholarly allegiance. No ANE composition was assigned a label that is anything like the terminology we use. This lack of classifying categories is matched by the absence of any argued theory of literature, its goals, and its many channels of interpretation.

Our own classifiers, however, have not been as reluctant to fix markers. Long ago, the works of Homer acquired the term "epic" (earlier: Epick, Epos); but only in the recent past began the accumulation of labels (many imported from distinct traditions) for narratives with heroic or historical characters. To begin with, there came to be subdivisions within "epic" (Assyriologists distinguish between "royal" and "historical" epic, featuring the heroics (however imagined) of actual kings and those dealing with all other heroes respectively; see Westenholz 1997: 16-24). But other labels are also used, among them "geste" (unfolding exploits, often assonantic), "legend" (fabulous story with historicizing touches), "saga" (family histories, occasionally heroic, often in multiple episodes), "folktale" (traditional, anonymous, and placeless narrative), and "romance" (not unlike legend, but accentuating intimate goals). Myths, said to rehearse cosmogonic themes involving supernatural characters, were set apart from epics, which were thought to 
enhance solidarity through paradigmatic human deeds. While myths were mined to explain theology and worldviews, epics delivered on ancient mores and informed on national aspirations. In fact, for no decent reason, when the Romantic Age was at its ripest, mythopoeism (the crafting of myths) was linked to folk speculation, while the production of epics was associated with elite, "nationalistic," drives. Yet, narratologically speaking, ANE myths and epics hardly differ, in form or structure, and even less so in the character-roles of protagonists. Both were regarded as equally historical (or not) and both equally challenge our capacity to disbelief. In some myths gods die and in some epics heroes are translated to heaven. It is not surprising to find Mesopotamian no less than Egyptian scribes as equally dedicated to praising the kingly acts of gods as the supernatural acts of heroes (Beaulieu 1993). Moreover, they shuttled at will motifs, themes, even globs of material between what we label myths and epics.

This unwillingness on the part of the ancients to concretize boundaries has spilled into our own scholarship. We now find "maximalists," for whom an epic must have breadth, a noble vision, and national or ethnic symbolism, and "minimalists," for whom the genre applies whenever two characters are tracked beyond a thousand words. Some specialists label a composition a myth and others an epic (Pongratz-Leisten 2001). Others, including such sophisticated literary analysts as Wasserman (2003) simply treat both as matched vehicles for fantasy. Still, discrimination between the two categories seems to be field specific: Egyptologists hardly recognize the epic in their literature; if at all, comparativists (like me) force it on them. Sumerologists apply the label on a distinct set of compositions (see list below), but not without protest (Michalowski 1992: 243-5; Edzard 1994). Specialists in Akkadian, Ugaritic, and to a lesser extant Hittite, readily assign compositions to one or the other category; but they are also likely to find "epic qualities" in both categories. Thus, Assyriologists do not find it anomalous to speak of the "Creation Epic" or the "Erra Epic" for compositions that are manifestly mythical. Biblicists who locate (fragments of) myths in the Bible blame Canaanite influence, denying Yahwists a capacity to forge their own fantasies. Likewise, those that find epic elements in scripture are inspired by analogies with Ugaritic narratives, thus prompting the suggestion that the saga of the patriarchs (and matriarchs) developed from a pre-biblical oral epic churned out during the Late Bronze Age. (For a range of opinions, see Conroy 1980; Talmon 1981; and Hendel 1987b.)

\section{Roster of Works}

In this Companion's ANE pages, you are likely to find those who construct the epic genre very strictly and so work with a very spare list. Yet in the literature one is apt also to meet with more elastic definitions and so with a broader list of applicable compositions. The following roster is of texts likely to be discussed in the literature (albeit not all in these pages), with at least one reference for each to readily accessible complete translations. An asterisk indicates those within the looser definition.

SUMER (Internet translations: www-etcsl.orient.ox.ac.uk/catalogue/cataloguel.htm) Lugalbanda and Enmerkar (from Vanstiphout 2003):

Enmerkar and the Lord of Aratta

Enmerkar and Ensuhgirana

Lugalbanda in the mountain cave Lugalbanda and Enmerkar (Lugalbanda and the Imdugud-bird)

Lugalbanda and Ninsun (from Jacobsen 1989)

Gilgamesh (from George 1999: 141-208):

Gilgamesh and Aga 
Gilgamesh and the Bull of Heaven

The Death of Gilgamesh

Gilgamesh, Enkidu, and the Nether World

Gilgamesh and Huwawa (in two versions)

AKKAD (Babylon and Assyria)

Etana (CS 1: 453-7)

Gilgamesh epics (all versions, from George 1999: 1-140)

Sargon narratives (from Westenholz 1997: 33-169):

Birth of Sargon (CS 1: 461)

Sargon, King of Battle (from Westenholz 1997: 102-39)

Sargon, the Conqueror (from van der Mieroop 2000).

Naram-Sin narratives (from Westenholz 1996: 173-332):

Naram-Sin and Erra

Great Revolt against Naram-Sin (many versions; see also Tinney 1995, Charpin 1997)

Cuthean legend of Naram-Sin, or Naram-Sin and the enemy horde (many editions)

"Historical" royal epics (select examples, mostly fragmentary; see full listing in Röllig 1978-90):

Zimri-Lim (not yet fully published)

Tukulti-Ninurta (from Foster 1993: 211-230)

Nebuchanezzar and Marduk (from Foster 1996: 299)

Adad-shum-uṣur (from Grayson 1975: 56-77)

Nabopolassar (from Grayson 1975: 78-86).

*Adapa (CS 1: 449-50)

*Atrahasis (Foster 1995: 52-77)

*Nergal and Ereshkigal (2 versions, CS 1, 384-90)

" "Epic" of creation (from Foster 1995: 9-51)

"Erra "Epic" (CS 1: 404-16)

*Anzu (from Foster 1995: 115-31)

*Ishtar and Șaltu ("Agushaya"; from Foster 1993: 81-91)

SYRIA (Ugarit)

Keret (Kirta) (CS 1: 333-343)

Aqhat (Aqhatu) (CS 1: 343-58)

*Ba'al and Anat (Ba'lu myth) (CS 1, 241-74)

ARAM

"The two princes (from Steiner and Nims $1985=$ "The revolt of Babylon," Vleming and Wesselius 1985)

\section{EGYPT}

Sinuhe (CS 1: 77-82; see Parkinson 1997)

Battle of Qadesh (CS 2: 32-8; see also pp. 38-40).

Astarte and the Sea (CS 1: 35-6; see Collombert and Coulon 2000)

The Destruction of Mankind (CS 1: 36-7)

The Two Brothers (CS 1: 85-9; see Hollis 1990)

The Foredoomed Prince (from Lichtheim 1976: 200-3)

Setne Khamwas tales (from Lichtheim 1984: 125-38 and 142-51)

Wen-Amun and Tale of Woe (from Lichtheim 1976: 224-30; Caminos 1977) 
HATTI (Anatolia)

The Queen of Kanesh and the Tale of Zalpa (CS 1: 181-2)

The Siege of Urshu (in Akkadian!; from Beckman 1995b)

Gurparanzakh (from Güterbock 1938: 84-90)

The Hunter Kessi (from Hoffner 1991: 67-8; possibly rehearsed in tablet EA 341 in the Amama archives www.tau.ac.il/humanities/semitic/ast.html

The Song of Ullikumi (from Hoffner 1991: 52-61)

The Song of Silver (from Hoffner 1991: 45-8)

\section{Process}

In discussing the process by which ANE literature developed meaning, it is convenient to distinguish among three steps: inspiration (generally conceived as recording literature), transmission (copying, but possibly also dictating from prototypes), and presentation.

\section{Inspiration}

ANE authors of narratives (in contrast to many writers of wisdom) did not acquire immortality for their work. As recovered in palaces and temples, several compositions are said to be inspired by inscriptions left behind by their hero, and this was deemed enough of a motivation for followers and emulators to keep their stories alive. (No one in antiquity would credit such material to folk derivation.) The attribution of personal authorship, however, operates on many levels: Sinuhe's adventures are claimed to be autobiographical, tout court. Gilgamesh is said (in one version) to have left behind a lapis lazuli tablet that may have inspired the carving of his nark (from Sumerian for "inscribed stone"; later also musarîu, "inscribed name"). In turn, the narû ostensibly provoked the bard into telling his story. The same for cursed Naram-Sin (the Cuthean Legend), who is cited as condemning an ancestor for failing to write his own naru as a potential guide. In a further twist, the bard quotes Naram-Sin's (fictitious) inscription as inspiring readers to write down their biographies.

Occasionally, however, we are treated to something more. The Erra "epic," which circulated in more copies than did Gilgamesh, tells of violence unleashed and sheathed, with consequences for deities and humans. The story is told from multiple angles, occasionally also from the first person (Erra himself); yet, in an attribution that is nicely woven into the narrative itself, just one person is credited with keeping it alive:

For innumerable number of years, praise of the great lord Nergal [Erra, a chtonic deity] and of heroic Ishum (will tell) that an angered Erra had planned to level the earth and to eradicate mankind, (but that) his adviser Ishum had cajoled him into leaving a remnant. Kabti-ilî-Marduk, son of Dabibi, is the compiler of his composition (kâsir kammišu). In just one night (God) revealed it to him, so that when he recited it on awaking, he skipped nothing from it, nor did he add a single line to it. Listening to it, Erra was satisfied with it; what his herald Ishum (said/did) pleased him, and, along with him, the gods in assembly are praising it.

Kabti-ilî-Marduk's effort was compensated, for the fifth and final tablet of his composition was often shaped into a talisman because it promised absolution and redemption. This sort of application is not at all uncommon in Mesopotamia for some of the versions of such works as Adapa, Etana, and Atrabasis served as prophylactic incantations before they reached us. 


\section{Transmission}

Yet attributing Erra to inspiration is deceptive. Although the Dabibi family is historical, Kabti-ilî-Marduk is likely not. (Elsewhere, he is implausibly associated with Ibbi-Sin, a king of Ur from around 2050.) Attributing a composition to a specific figure was by no means unknown - Enheduanna, daughter of Sargon of Agade (2300) is the earliest named "author" on record - but we are dealing here with a phenomenon increasingly favored in the first millennium $\mathrm{BCE}$, in which pseudanonymity is conferred on compositions, even those allegedly dependent on narûs. Scribes (themselves anonymous) attributed important works to personalities in the past, fictive or legendary. They did not do so because they wished to give due credit; rather, like us, they had powerful attachment to historicity. By matching epics to authors, scribes and scholars attach narrative flesh to annalistic bones and make paradigms out of barely recalled lives. For this reason, despite the intimation that Gilgamesh's own story inspired his epic, a first millennium BCE catalogue of works (Lambert 1962) claimed that it was written "on the instruction of Sin-leqi-unninni, the lamentation specialist." Whatever his historicity (scholars would place him in the Kassite period, so around 1300 в past until, in a document from the Seleucid period, he was made a scholar in Gilgamesh's court, hence privy to Gilgamesh's own story (Beaulieu 2000): a neat solution all around. Conferring pseudanonymity on inherited lore also tightens membership around the scribal guild. This is obvious in Mesopotamia where the shift from scribal schools to bureaucratized temple and palace services brought with it an increasingly proprietary attitude to texts and the production of texts, and the heroes of history became the keepers of that history. Somewhat similar is what occurred in Jewish lore. Despite ready acceptance of a divinely inspired literature, talmudic rabbis nevertheless assigned writers to individual books of the Bible (Babylonian Talmud baba bathra 14a-14b). The gist of all this is that, unlike the scribes of antiquity, we cannot confidently match any of the works listed above (with the possibly exception of the Ugaritic material) to a specific individual.

We often find names of scribes in colophons (scribal subscription), but cannot always agree on their role. For example, a colophon to the Ugaritic Baal and Anat states: "Ilimalku of Shuban is the $\operatorname{spr}$ (scribe?; writer"), Imd (disciple") of Attanu, the diviner, Head Priest, Head Shepherd (a military title), t $y$ (of Tha' $\left.i^{?}\right)$..." The vocabulary in italics is slippery. Does $s p r$ tell that Ilimalku is its creator, its editor, or its copyist? What does $l m d$ say about his connection with Attanu? Is the last his teacher, his (oral) source, or merely his sponsor? Each answer, alas, is plausible. Tantalizing is the fact that the Ugaritic narratives, though recovered from different locations, are so far without duplicates, even when recovered from different "archival" rooms; so they were possibly created just then rather than copied. Yet a number of them seem scripted by the same hand, presumably Ilimalku's. If so, the two observations would encourage us to credit Ilimalku (if not Attanu) with imagining this literature, albeit inspired by native lore.

More interesting is the issue as raised by the many versions of the Battle of Qadesh, which report Ramses II's alleged triumph, in his fifth regnal year, over a potentially devastating defeat. The event is known to us from many sources: carvings on the walls of several temples with lively captioned scenes, an overall commentary on what they depict, and a parallel lyrical version of the same. Later (how much is disputed) the lyrical version was rehearsed at least twice on papyrus, the better preserved of which [P. Sallier 3] containing the following colophon, "This text (was written) in Year 9 ... of/ for... Ramesses [II]. It was successfully completed. [This copy is] For the $k a$ [spirit] of Amenemone, the Chief Archivist of the royal treasury, and of Amenemwia, the Scribe of the royal. Made by Pentaweret, Scribe for..." Research into the period (Spalinger 2002) has shown that much leeway was taken by Pentaweret in modifying the narrative. 
From his works on other compositions, it is even possible to credit Pentaweret (perhaps also his sponsors) with a stake in the welfare of pharaohs who were challenged by enemies.

\section{Presentation}

How to imagine the presentation of composition has been especially challenging to scholarship, for we can find hints in each composition to suggest that it was read, with eyes or mouth, quietly or aloud, recited or chanted, accompanied or not by musical instruments. Yet the evidence we draw from inspecting the documents themselves is but a fragment of what may have occurred during a presentation. We cannot recover the tonal inflections, the pacing, the gestures, and the body language that added meaning to a particular phrase or pumped emotion into a presentation. Morever, if chanting (a capella or not) or miming rather than just declamation was involved, the performer will have had many opportunities to expand effectiveness.

Occasionally, one reads that all narrative poetry was performed. This is said about Sumerian compositions even when there is doubt about the language's living status; see Black 1992, where performance of compositions is taken for granted. It is likewise attributed to some Egyptian texts, even when their archaism or formalism is likely to have impeded their comprehension. Sometimes staging (of some sort) is presumed, as for example regarding the Semitic Gilgamesh, because a relatively small cast is assigned a great number of dialogues over a large composition. In some of the Ugaritic texts, we find rubrics instructing a return to specific segment of the story, suggesting a manipulation of a presentation, perhaps implying declamation if not staging. There are hints that some works were chanted, and may have been written for singing. Enheduanna is inspired to praise her goddess in the middle of the night, her words repeated by a singer the following noon (Exaltation of Inana, 138-40). King Shulgi of Ur (2100) claims to be "a composer of songs and a composer of words," so, hendiadycally, a "composer of sung words" (Shulgi B: 363-365, see: www-etcsl.orient.ox.ac.uk/cgi-bin/etcslmac.cgi?text=t.2.4. 2.02\#).

No less challenging is deciding who sponsored presentations and whom they addressed. What does it mean, we ask, when colophons give the name of scribes and place them at a temple or at the court of a ruler (as is the case of Ilimalku or his mentor)? Were they set there because their creativity was appreciated? Or was it because they dependably produced what their sponsors required? Were they expected to deliver functional works that steered people towards communal identity? Or were they appreciated for crafting mimetic products that stimulated personal emotion? In the case of the Ramses' Qadesh poem if, as it has been shown, Penteweret did not always understand the original (or its copy) from which he worked, he may have been fulfilling an obligation or a specific request rather than responding to a creative urge. We might draw a similar conclusion whenever we meet with versions of the same tale. Segments of Etana, Atrabasis, Gilgamesh, and of some the Naram-Sin tales can differ appreciably from each other, and it is tempting to believe that the differences are there because they are addressing different audiences. (Compare how the Tristan narratives adapted to a changing audience.) We have hint of the process when Old Babylonian scribes dealt with Sumerian stories about Gilgamesh, normally each complete in itself. For example, "Gilgamesh, Enkidu, and the Nether World" normally features a bleak account of life after death. In their version of the story, however, the scribes of Meturan (a town) added an appendix that tied this tale to another, "Gilgamesh and Huwawa," in which Gilgamesh searches for the meaning of life; see Cavigneaux 1999: 256-7. Was it taste of the time that made them resist the stifling of hope?

While the many versions of the Semitic Gilgamesh epic share characters and central episodes, they differ in how they begin and end, in their development of character, and in 
allocation of episodes (Tigay 1982 and Abusch 2001a.) In particular, the first millennium version is endowed with a psychological dimension hardly discernable in the older version, recorded two-thirds of a millennium earlier. For example, the seduction of the feral Enkidu unfolds pedagogically in the older version as the prostitute and shepherds patiently bring him into adulthood. In the later version, however, maturation occurs to Enkidu when his previous world rejects him and he has no choice but to accept human companionship. Moreover, an ironic link between Gilgamesh and his audience is totally new in the later version. It is forged when the bard opens by alerting his audience to Gilgamesh's flaws no less than his virtues, so inviting an audience to be judgmental as he makes choices (Sasson 1992).

Some scholars believe, however, that many of these texts pleased a very specialized audience, whether it was the circle of scribes who took pleasure in their own creations or of the elite at the royal court. In particular, the deeds of kings of Early Dynastic Uruk were deemed paradigmatic by rulers of Ur half a millennium later. There, King Shulgi took credit for guiding bards towards authenticity: "I swear no one has ever put anything mendacious about me in my hymns; no one has embellished my prayers with achievements that I have not matched; I, Shulgi, have never allowed exaggerated praise of power to be put in a song" (Shulgi E, 40-6, at: www-etcsl.orient.ox.ac.uk/cgi-bin/etcslmac.cgi? text=t.2.4.2.05\#). We can imagine court poets testing their mettle when singing the heroics of their nearly contemporaneous patrons Pharaoh Ramses II, Tukulti-Ninurta of Assur, or Nebuchadnezzar I of Babylon (see list above). The royal epic genre, in fact, was established centuries earlier, in Egypt since the Middle Kingdom, and in Mesopotamia at least since the eighteenth century в С , for we have an as yet unpublished example wherein a minor ruler of Mari (Zimri-Lim) is lionized within a few years of usurping the throne. Bards, it seems, found inspiration even when depending on dole.

\title{
Literary Issues
}

We argue circularly whenever we address the nature of an ANE "epic." We justify the existence of the genre and assign narratives to it because we locate in the target examples literary characteristics - motifs, themes, structures, and modes - that were charted in classical and medieval literature long before ANE literature was seriously studied. The application therefore can be ungainly. Nonetheless, it might be useful in this survey to lightly comment on some of these features with minimal illustrations.

\begin{abstract}
Motifs
Motifs are essential components in narratives. Sequences of actions (by animates or not) coagulate into a motif, a coherent tale-unit that achieves individual integrity, often becoming crucial in moving the plot. Scholarly awareness of such an element anteceded the birth of folklore as a discipline; but more precise cataloguing of the repertoire was due to Antti Aarne in 1964 (see Aarne and Thompson 1981) and to Stith Thompson (1955-8). Since then ANE specialists (for example, Gaster 1969; Irvin 1978; Hollis 1990) have isolated motifs within ANE literature for comparison, across and within literature. Here, the issue of artistic resiliency and the capacity to adapt arise, as writers of antiquity (no less than today's) can poach phraseology and motifs that cut across a number of genres. Thus, the intimately autobiographical Apology of Hattusilis III, king of Hatti (thirteenth century) is so steeped in the language of the heroic, including the motif of combat through champions, that its historicity is compromised (van den Hout 1995). The same can be said about the "autobiography" of Idrimi, from Late Bronze Age Alalah in Syria (Oppenheim 1969: 557-8). Its storehouse of literary vignettes, such as
\end{abstract}


the triumphing youngest child and the questing hero, has almost convinced me to place it among Canaanite (or Syrian) literature. Egyptian autobiographies are thick in motifs for virtue (care for the poor, obedience to superiors, foolish bravery during combat, etc.) that often coincide with what is assigned to the heroic. While we can cite few motifs that were knowingly shuttled across linguistic borders (across Sumerian and Akkadian is an obvious exception), some compositions such as the Epic of Gilgamesh are repository for globs of narrative units that were transferred across genres.

One can find images that evoke the heroic in material that is not normally treated as literature. In the letters from Mari (admittedly more loquacious than others), there is a dossier on the marriage of King Zimri-Lim that can easily be placed alongside Keret or the biblical Isaac saga. In them we meet anxious schadchans, complicated voyages to distant lands, presentation of gifts, veiling the bride, anxious parents, trekking back, and preparing the bridal chamber. We may never know how much of Gilgamesh's story was known to a vassal who allowed that because of his lord's sensitivity and strength, "my gray hair turned black and I found youth. My heart was rejuvenated beyond compare and my reputation spread all over Idamaras" (Kupper 1998: no. 145). And when diplomats report on their experiences, they can be omniscient in their knowledge of events or of motivation and can fill their canvas with characters that are nearly stock, including dense rulers, darkhearted courtiers, and scheming enemies. Their rhetoric can emulate the best found in heroic tales, with people "shaping their mouth" to speak, repeating acts a set number of times (seven is a good one), and indulging in the bold repartee or the bon mot (Sasson 2001).

With such adaptability in mind, it is not surprising that even the briefest composition in our roster has proven to be a storehouse of motifs. What to do with them then becomes an issue. While no researcher today would approve of Peter Jensen's deriving of practically all of human literature from Gilgamesh antecedents (1906-1929), it remains obvious that accumulating individual motifs for comparison rarely deepens our sense of how compositions mean or evolve. (How useful is it to know that, throughout the globe, heroes of literature are said to survive the murder of their parents, that they confront evil, that they display courage or cleverness, or that they win the hearts of their destined?) Ex-cathedra methodological formulations have sought to sharpen the comparison of motifs, among them that there should be a unity of time and space with the material in which they are embedded or that there should suggest a correspondence of contexts (social, cultural, political, or the like) in their derivation or application. Such considerations often force the affinity among motifs to remain within ANE confines. More interesting, because they allow breaking away from time or place constraints, are those studies (influenced by the work of Vladimir Propp) that establish comparison only when strings of motifs bead into in a logical sequence, a series of which form distinct tale genres, depending on the syntax with which they connect. (See below, under "Modes").

\section{Themes}

It is not always possible to uncover the themes of ancient epic, not just because many gaps mar the examples at hand, but because we cannot be certain that our judgment about them correspond with that of its original hearers. Nonetheless, some prominent themes can be mentioned.

Continuity of a family line is certain to be one of them, albeit displayed in a broad variety. In Keret, it is frontal: the story opens on a king's line facing extinction. This is resolved when the king's hard-earned bride produces a potential heir who, alas, proves so wanting that Keret curses him, hence again compromising the future. This exposition of the theme is purposely unsatisfying because it is made subservient to another theme that 
develops an object lesson for Keret: a distressed king makes a vow that he neglects to fulfill when times get better, with the expected consequences. Continuity is also a major theme in another Ugaritic tale, Aqhat. King Danel's plea for a son is answered, but dynastic continuity is endangered when the son impudently angers a goddess. Whether in Ugarit such unhappy endings were favored by audiences or parabolically reflected historical events is beyond us to easily recover. The continuity theme gives ample occasion for transmutation: The threat of extinction because of infertility, a wife's sterility (heavily invested in biblical lore), or simply on facing death, might prompt heroes to alter human fate, by storming heaven (Etana), by arresting aging (Utnapishtim in Gilgamesh), by partaking divine fare (Adapa), by regaining youth (potential in Gilgamesh), or by reincarnating (Bata in The Two Brothers, Ahwere in the Setne Khamwas tales). Immortality, resurrection, and metempsychosis are other exploited alternatives.

Linked to this theme is that of Reputation or Name. In ANE lore, reputation is hardly limited to a single lifetime; rather, it reflects on past and future generations and must not be halted by one person through ignoble deeds or sloth. Preserving or expanding a reputation effectively neutralizes the limitations of human life. In this sense, Gilgamesh is less about longing for objects of desire or about halting death as about extending prestige, initially as the reward for courageous deeds through personal efforts, but eventually as the permanence of communal achievement through thoughtful leadership. This heightening of status can be acquired by testing the limits of human endurance, as in the materials concerning the Sumerian Gilgamesh and Lugalbanda, and the Egyptian Sinuhe. It can also be achieved by display of indomitable will when disorder threatens, as in the stories involving Sargon of Agade and Hattushili of Hatti (Siege of Urshu). This resolve can be displayed agonistically, as in the Naram-Sin sagas: despite his name ("Beloved of the god Sin") Naram-Sin slights the gods and pays for his hubris by losing political prestige (unhistorically, his kingdom is said to collapse); but he also gains immortality as a fine example of an Unheilsherrscher, a misfortune-prone elect of the gods. A variant vein, the taming of chaos, comes to be a major theme in what is labeled the "historical" or "royal" epic, involving kings and pharaohs who marshal and deploy their forces against barbarian hordes no less cosmically, symbolically, and triumphantly than do the gods of theogonies.

\section{Structure}

How a narrative unfurls a plot over a number of sequences without sacrificing literary cohesion owes much to the discrete use of structural devices. In most examples, the matter is about form, how material is organized to achieve a derived effect. However, in a few cases, such as the Semitic Gilgamesh and some of the Naram-Sin material, such devices give coherence to a broad canvas. (This is especially true if a work is orally communicated.) Among the storehouse of available devices to realize narrative integration is the periodic renewal of scenes, such as those around a banquet, or the recurrent repetition of a situation or an idea, such as those that are experienced during travel.

\section{The banquet}

In real life, banquets give a special rhythm to affairs of state or of family, creating bonds and solidifying loyalty. (For agreeable essays on Banquets et fêtes au Proche-Orient ancien, see the Dossiers d'archéologie 280, February 2003.) In ancient lore, however, banquets serve to focus on a critical juncture of a story (as when gods banquet at the crowning of Marduk in Enuma Elish, or when Keret is assured progeny by banqueting deities). Often they offer an ironic setting for violent acts against guests (frequent in the Bible, as in the 
murder of Amnon, 2 Sam. 13: 28-30, but also elsewhere as in the Hittite Gurparanzakh). Banquets also serve to punctuate different moments of an unfolding drama (as when Keret's nobles set a destiny for his throne). They can also be used as brackets for reversal of fortune, as in the Lugalbanda tales when, left to die, the hero uses food to attract divine goodwill. In some narratives (for example, the biblical Esther and the Demotic tales of Setne Khamwas), banquets can be displayed virtuosically, punctuating major moments of a tale. Banquets, too, can be veritable storehouse of motifs: crowning (or uncrowning) of kings, clothing (or unclothing) of guests, wining friends, inebriating foes, challenging enemies, empowering kin, and altering the status of individuals(but always as thresholds for major unfolding of plots (Grottanelli 1989).

\section{The journey}

In lore as in monumental inscriptions, the activities of kings that are most often deemed heroic and worthy of emulation are those that recount many voyages of conquest termed unique or never previously attempted. Here is what Sargon boasts (Birth of Sargon):

[For $\mathrm{x}$ ] years I reigned as king. I ruled and governed the black-headed folk. With copper tools, I traversed rugged mountains. I ascended high mountains and cut through low mountains. Thrice I circled the Sealands; Dilmun surrendered... Any king that comes after me [and compares to me] should rule for [x years], should rule the black-headed folk, should traverse rugged mountains with copper tools ... (after Westenholz 1997: 42-5).

The most elaborate narratives can be built around a simple notion: someone goes far from home and then comes back. So, we might consider grist for our mill any imaginative narrative (prose, lyrical, or poetic) in which someone (or some folk) undertake distant journeys though which they acquire status, wisdom, or insight. Naturally, we must enter qualifications: the journeys must be demanding physically but possibly also psychologically (though not necessarily spiritually), with all the complications and unexpected challenges that such experiences entail. When told, it should partake something of the grand gesture and of the ceremonial. From this perspective, it is noticeable that a good number of the compositions in our list divide neatly on how pronounced or integrated is the journey as a plot structure. In some myths, the travel of gods furnishes etiologies for festival rituals ("Nanna-Suen's Journey to Nippur") or deliver theological or cosmological explanations ("Nergal and Ereshkigal"). Journeys are intrinsically interesting as they convey (imaginatively or not) information about distant places. They are nicely evoked in tales (Egypt's Sinube and The Foredoomed Prince) and in pseudo-autobiographies (Egypt's Travel of Wen-Amun and Tale of Woe), where they establish a remarkable carving of foreign space as imaginatively antithetical to native topography (Loprieno 2003); but they can also serve as vehicle for the heroic where they invariably also acquire a psychological dimension.

The journey is an essential component of the Sumerian tales, ostensibly about Uruk and its chief deity, Inanna, but really about its heroic rulers. However, none of our tales plots the journey conventionally. In two about Lugalbanda ("Enmerkar and the Lord of Aratta", "Enmerkar and Ensuhgirana") that are likely to belong to a single cycle, crossing space to arrive at a destination (the city of Aratta) is itself the locus of significant developments (see Vanstiphout 2002). In one ("Lugalbanda in the mountain cave"), abandoned by his troops to die Lugalbanda makes discoveries about his capacity to survive. In a dream sequence that itself is another journey, he learns how to deal properly with the god. (Dreams often occur bunched repetitively in narratives, among them Kessi, Gilgamesh, and frequently in the Hebrew Bible, raising the stakes for a hero who rarely interprets correctly.) In another ("Lugalbanda and Enmerkar"), once again left behind, Lugalbanda accepts the power of speed after showing proper respect to the great Anzu (or 
Imdugud, a pre-anthropomorphized urge). Later, he uses that gift to personally achieve victory over Aratta. In the two tales about Enmerkar, however, the hero does not journey between his city and Aratta, but his henchmen, messengers and magicians, do.

While not all the Sumerian Gilgamesh tales are plotted around travel, one "Gilgamesh and Agga", brings foes to the gate of Uruk while two others rehearse a line that will be featured in the Semitic version. "Gilgamesh and Huwawa" takes Gilgamesh to the "land of the living" where he ends Huwawa's life, for which he earns the god Enlil's hatred. (Although the language is Sumerian, this composition is open-ended, replaying themes and motifs developed in the Semitic Gilgamesh from which it may have been adapted, rather than the other way around.) Another tale, "Gilgamesh, Enkidu, and the Nether World", grafts an epic segment to a mythological introduction. Here Enkidu is the traveler, becoming the eyes and ears of Gilgamesh as he reports on the Nether World. Similarly attached to a mythic initial situation is the story of Etana whose journeys to heaven and back are background to a favored theme, the immortality of the human species (but not of individuals), a theme that is at the core of the Hebrew Eden narrative (Sasson 2000). Adapa explores a somewhat similar theme, when its hero crosses boundaries and appears before the gods in heaven.

The journey is heavily invested as a plot structure in other compositions as well. Israel brackets its entire story between voyages from Babylon to the promised land: one brings Abram from Ur of the Chaldeans, the other the exiles from Babylon. Within this huge canvas, many voyages (of Jacob, of Joseph, of David) are replayed, with different import on the narratives in which they are embedded. Most ambitious among these are the trips into and out of Egypt that not only illustrate God's saving grace, but also occasion the delivery of all the laws that Israel will ever need. In Canaanite lore, Keret launches an expedition to retrieve a destined bride and makes a vow along the way that he fails to fulfill, thus initiating reversal of his fortune. Disguised as an autobiography of confession, Sinube is epic in goal and proportion, centering on exploits of survival and attachment to the homeland. Fearing implication in a crime against pharaoh, Sinuhe escapes Egypt and finds status among Asiatics. Welcomed back by pharaoh, Sinuhe returns home where alone his destiny can unfold. (Such events are realistic enough to be replayed in the life of the composer John Dowland.) Interestingly, the journeys from Egypt and back contribute to the plot by embedding within their unfolding five different explanations - from at least three differing perspectives - for Sinuhe's initial flight, and thus they permit endless speculation on his motivation.

In all its versions, the Semitic Gilgamesh is built around voyages, but most sharply so in a series where it exhibits an exceptional accent. In the first half of the epic (tablets I-VI), voyages are either generated by the plot (Enkidu's arrival at Uruk) or heroic (journey to the cedar forest), the last stretching over a number of tablets. They are reversed in the return to Uruk and in the death of Enkidu. From that point, the voyages take on a surrealistic dimension paralleling the distraught mind of the hero. Disheveled and wasting away, Gilgamesh embodies his friend's unpromising beginnings and for almost a third of the epic is in perpetual roaming. At the outset he begs for a dream, but in a cryptic scene whose ambiguity and centrality evoke Jacob's Jabbok struggle, Gilgamesh rises to battle unknown enemies (his own fears?). It is conceivable that the epic's remaining travels, to the end of the earth and beyond, are but one night's hallucinations.

\section{Modes}

As it concerns the deeds of heroes, real or imagined, some epics find it convenient to depict their adventures as pages (single or multiple) from their "biographies." As narrated, the 
events carry the hero beyond specific hurdles. Ramses II, Tukulti-Ninurta, Hattusili I (in "The siege of Urshu") are among many who must surmount deceit and villainy, staples in sagas that concern kings. But protagonists must also counteract manifest lack (Sinuhe's distance from home, Lugalbanda's hunger and abandonment) or fulfill a need (most often, a desire for an heir, as in Keret, Aqhat, The Queen of Kanesh, and the Tale of Zalpa). Despite their potential for failure (which of course hardly ever materializes), the subjects of such biographic pages replay themes that can be paradigmatic, archetypal, or simply conventional, all meant to multiply potential linkage with their audience.

The biographies themselves can be emblematic, episodic, or melodramatic (Sasson 1984). The first, the emblematic biography, is rarest in that one specific event in the hero's life is exposed for its parabolic potential. It is also the most contested, for such narratives skirt the epic genre and so may cogently be placed among other genres. This is the case of Adapa, wherein the hero's personal gain (a successful appeasement of the gods) is his species's loss (mortality assigned to human beings). In ANE literature, however, most commonly we meet with the episodic mode in which a single hero is the subject of a series of self-contained, integral tales. Characters, even plot lines, may resurface in a number of them; but no detail from one is necessary to the denouement of another. Because of its clay tablet medium, episodic narratives are perfect for Mesopotamia, so we have the Sumerian Enmerkar, Lugalbanda, and Gilgamesh tales as well as the Akkadian stories centering on the kings of Agade. But this mode can occur also in Egypt as in the demotic stories regarding Setne Khamwas, a son of Ramses II, who acquired folk status as a seeker of secrets better left to the gods.

In biblical lore, the story of Abraham is a perfect example of the episodic biography. Between Genesis 12 and 24, we have series of tableaus that are barely dependent on a chronological sequence and oblivious to cogent transitions. But each has a specific goal, delivering diverse manifestations of the heroic character: resourceful, cunning, martial, generous, magnanimous, and argumentative, but also indecisive, duped, and henpecked.

More appealing to us is the melodramatic biography. Rather than conveying specific behavior, it explores the inner world of a hero, progressively and deliberately, achieving a portrait that is unique and non-transferable. To this mode belongs such exceptional works as the standard Epic of Gilgamesh and the biblical stories of Jacob and of David. This portraiture is achieved not through authorial intent but through the sophisticated editing of inherited or adapted tales. Early on, the destiny of the hero is presented (by the bard in Gilgamesh, through an oracle for Jacob, and by divine selection for David), setting a clear path toward its fulfillment. There is a tendency to shape into the narrative an emotional fault-line, with the hero undergoing major psychological transformation just as he triumphs against all odds. No sooner does Gilgamesh vanquish Humbaba than his world is jolted by the death of his companion, Enkidu. The epic shifts course at this point, moving from the realistic (battle against a foe, in an earthly setting) to the surrealistic (battle against fear, at the edges of consciousness). The same can be said about Jacob and David who have it all before their children wreck their hopes and aspirations.

\section{Epic: Theirs into Ours}

But for the stories of Israel, ANE literature died two millennia ago, largely disappearing from public knowledge, victimized by the suppression of polytheistic creeds and a casualty of scripts no longer decipherable. When this literature returned to public attention, ironically enough it was largely because it was linked it to the Bible. Some of this linkage was well motivated, for example Hermann Gunkel's recovery of the Bible's pre-literate stage though comparison with Near Eastern literature. Others had sinister goals, for 
example Friedrich Delitzsch's distortion of Assyriology to prove the Bible (in fact, Judaism) "a great deception" (Larsen 1995). However misguided, P. Jensen's drive to center the Epic of Gilgamesh within world literature did bring it to wide notice $(1906,1929)$. At first intrigued mostly by the Epic's flood segment, the public eventually took it to heart, resonating to its humanism, its existentialism, and its manifold transfigurations of desire. (It might not have fared as well had it surfaced a century earlier, when sensibility differed.) Segments of Gilgamesh are now featured readings in secondary school and oodles of Gilgamesh for kiddies can now be purchased. Aside from countless translations (see the chapter by Armstrong), some more faithful or poetic than others, in dozens of languages, the epic has spawned: novels (Robert Silverberg, Gilgamesh the King, 1984), retellings (Stephan Grundy, Gilgamesh, 2000), avatars (Joan London, Gilgamesh, a Novel, 2001; Eduardo Garriques, West of Babylon, 2002), poetry (Charles Olson; see Maier 1983), operas (Per Nørgard, Gilgamesh, Voyages into the Golden Screen, 1974; Stephen Dickman, Gilgamesh, an Operatic Ritual, 2002), oratorio (Bohuslav Martinů, Epic of Gilgamesh, 1955), ballet (Augustyn Bloch, Gilgamesz, 1968), pantomime/dance (numerous, including one by Teresa Ludovico, Gilgamesh, 2003), and videos (Scott Noegel, Gilgamesh XI: An All Digital Film, 2000). A Hollywood dressing cannot be too distant in the future.

In itself this contemporary absorption in Gilgameshiana is interesting. The Epic that has inspired us was far from the Mesopotamian scribe's most copied composition (omens were) and hardly was the national epic that our great scholars want it to be. Moreover, for a substantial period of time, the Epic was a composite that never existed in any single version, so was a vessel for compacted material with resulting contradictions and tensions that now strike us as appealingly contemporary. Nonetheless, Gilgamesh remains the sole example in our list of ANE compositions to have reached a discerning audience or to have provoked sustained comparison with classical parallels (Abusch 2001b). The Creation "epic" similarly serves biblical comparison, but not always for the best reasons; Sinuhe has inspired a novel that was turned into a movie and the "Birth of Sargon" is dragged into every Exodus commentary.

How will this literature, which scholars have so lovingly resurrected, fare in our cultural future? My sense about its prospects is not encouraging. To begin with, its fragmentary nature (tablets and papyri are full of inopportune breaks) and its grammatical density (Sumerian and Ugaritic are not yet exact sciences) compromise a full appreciation. But we also generate the hurdles against its acceptance. We are trained to focus on authors as vessels for genius and are unnerved by a literature that is anonymous even when assigned composers. We applaud narratives with a taut pace, minimal repetitions, a rich vocabulary, and scintillating dialogue, but often meet with opposite manifestations. We want literature to be a window to the ambitions and the anxieties of the past, and are annoyed when it is anchored in punctual or local context. As a result, beyond academia we analyze this literature's repertoire of plots and characters with detachment, resist understanding its aims or point of view, and feel little urgency to incorporate its examples into the streams of modern culture. It seems to me that for a while longer this literature will remain alien to our larger public.

\section{FURTHER READING}

In a reference set (such as this) that focuses on a single subject, you are likely to find multiple reference to the same resources. With apologies for any duplication, I offer the following suggestions. (For fuller version of each entry, see the bibliography.) 
For overviews and background, you cannot do better than read the chapters in the multi-volume reference set Civilizations of the Ancient Near East (Sasson 1995). It contains many chapters on the history, literature, art, sociology, and economy of the cultures that are of most interest to us. The contributors are all distinguished specialists and write a clear prose that is not compromised by footnotes. In English there are two collections of ANE texts in translations: Pritchard's Ancient Near Eastern Texts Relating to the Old Testament (ANET, 1969) and Hallo and Younger's The Context of Scripture $(1997,2002)$. But there are also volumes that collect translations by individual cultures, such as Foster 1993 (repr. 1996); Hoffner 1991; Lichtheim 1976; 1984; and Vanstiphout 2003.

Specialized studies on literature (not to say epic literature) are relatively few. Those who believe there is a biblical epic are served by Hendel's The Epic of the Patriarch (1987b). For Sumer there is Black's Reading Sumerian Poetry (1998). For Mesopotamia, see Westenholz 1997 and Grayson 1975. For Ugarit, see Parker 1997.

Older notions of the epic were often fixated on collecting and comparing motifs that allegedly traveled from one culture to another; good examples are Gaster 1969 and Irvin 1978. Unfortunately, we mostly have collections of articles on newer perspectives regarding the epic, and not all their contents of equal merits: see Parker 1989; Loprieno 1996; and two collections by Vogelzang and Vanstiphout (1992 and 1996). Worth exploring is Spalinger 2002. 